\title{
In situ transmission electron microscopy studies of the kinetics of Pt-Mo alloy diffusion in $\mathrm{ZrB2}$ thin films
}

I Jouanny, Justinas Palisaitis, C Ngo, P H. Mayrhofer, Lars Hultman, Per O A . Persson and S Kodambaka

\section{Linköping University Post Print}

\section{Tweet}

N.B.: When citing this work, cite the original article.

Original Publication:

I Jouanny, Justinas Palisaitis, C Ngo, P H. Mayrhofer, Lars Hultman, Per O A. Persson and S Kodambaka, In situ transmission electron microscopy studies of the kinetics of Pt-Mo alloy diffusion in ZrB2 thin films, 2013, Applied Physics Letters, (103), 12.

http://dx.doi.org/10.1063/1.4820581

Copyright: American Institute of Physics (AIP) http://www.aip.org/

Postprint available at: Linköping University Electronic Press

http://urn.kb.se/resolve?urn=urn:nbn:se:liu:diva-100316 


\title{
In situ transmission electron microscopy studies of the kinetics of Pt-Mo alloy diffusion in $\mathrm{ZrB}_{2}$ thin films
}

\author{
I. Jouanny, ${ }^{1}$ J. Palisaitis, ${ }^{2}$ C. Ngo, ${ }^{1}$ P. H. Mayrhofer, ${ }^{3}$ L. Hultman, ${ }^{2}$ P. O. Å. Persson, ${ }^{2}$ \\ and S. Kodambaka ${ }^{1, a)}$ \\ ${ }^{1}$ Department of Materials Science and Engineering, University of California Los Angeles, Los Angeles, \\ California 90095, USA \\ ${ }^{2}$ Department of Physics, Chemistry, and Biology (IFM), Linköping University, S-581 83 Linköping, Sweden \\ ${ }^{3}$ Institute of Materials Science and Technology, Vienna University of Technology, A-1040 Vienna, Austria
}

(Received 5 June 2013; accepted 9 July 2013; published online 16 September 2013)

\begin{abstract}
Using in situ high-temperature (1073-1173 K) transmission electron microscopy, we investigated the thermal stability of $\mathrm{Pt}$ and $\mathrm{Mo}$ in contact with polycrystalline $\mathrm{ZrB}_{2}$ thin films deposited on $\mathrm{Al}_{2} \mathrm{O}_{3}(0001)$. During annealing, we observed the diffusion of cubic-structured $\mathrm{Pt}_{1-x} \mathrm{Mo}_{x}$ (with $x=0.2 \pm 0.1$ ) along the length of the $\mathrm{ZrB}_{2}$ layer. From the time-dependent increase in diffusion lengths, we determined that the $\mathrm{Pt}_{1-x} \mathrm{Mo}_{x}$ does not react with $\mathrm{ZrB}_{2}$, but diffuses along the surface with a constant temperature-dependent velocity. We identify the rate-limiting step controlling the observed phenomenon as the flux of Mo atoms with an associated activation barrier of $3.8 \pm 0.5 \mathrm{eV}$. (C) 2013 AIP Publishing LLC. [http://dx.doi.org/10.1063/1.4820581]
\end{abstract}

Fabrication of advanced structural materials systems such as thermal barrier coatings ${ }^{1-4}$ and ultra-high temperature ceramic ${ }^{5-7}$ components often requires joining or sintering of dissimilar materials. For example, refractory oxides are bonded to metallic super alloys in thermal barrier coatings, and sintered composites of refractory borides ${ }^{8}$ and carbides $^{9}$ are attractive for aerospace applications. The common methods employed to improve the wettability and adhesion at the heterogeneous ceramic-ceramic and metal-ceramic interfaces involve physical and chemical modification of the interfaces via deposition of a low-melting and/or a reactive metal. ${ }^{10,11}$ Given that the operation life-time and performance of any of these structural materials systems depend on the thermo-mechanical and chemical stabilities of the interfaces, a fundamental knowledge of the interfacial thermodynamics and reaction-diffusion kinetics is valuable. Here, we focus on the thermal stability of $\mathrm{ZrB}_{2}$ in contact with metals such as Pt and Mo.

Motivation for the present study stems from the fact that refractory borides such as $\mathrm{ZrB}_{2}$ and related alloys are used in airframe leading edges and reentry vehicles due to their ultra-high melting temperatures $(>3000 \mathrm{~K})$ and excellent high-temperature strength. ${ }^{6,12}$ Typically, these structural components are prepared out of ceramic powders, which are mixed with metals or metal silicides to promote sintering and to enhance their functionality. ${ }^{8,11,13-19}$ Growth and characterization of $\mathrm{ZrB}_{2}$ thin films are also of interest for potential applications as decorative coatings and diffusion barriers in microelectronics. ${ }^{20,21}$

In this letter, we report results from in situ transmission electron microscopy (TEM) studies of thermal stability of $\mathrm{ZrB}_{2}$ thin films in contact with $\mathrm{Pt}$ and Mo. Cross-sectional TEM (XTEM) samples were prepared using focused ion beam (FIB) milling of polycrystalline $\mathrm{ZrB}_{2}$ thin films sputter-deposited on $\mathrm{Al}_{2} \mathrm{O}_{3}(0001)$ substrates and attached to

\footnotetext{
${ }^{\text {a) }}$ Author to whom correspondence should be addressed. Electronic mail: kodambaka@ucla.edu
}

Mo TEM grids using Pt. In situ TEM images, selected area electron diffraction (SAED) patterns, and electron energy loss spectra (EELS) were acquired during annealing at temperatures $T_{\mathrm{a}}$ up to $1173 \mathrm{~K}$. At $T_{\mathrm{a}}>1173 \mathrm{~K}$, we observe changes in the TEM image contrast corresponding to the formation of an interface in the $\mathrm{ZrB}_{2}$ layer. We find that this interface moves unilaterally along the film away from the end of the sample attached to the TEM grid at a constant temperature-dependent velocity. Using a combination of SAED, EELS, and energy dispersive spectroscopy (EDS) data, we identify the diffusing material as face-centeredcubic $(f c c) \mathrm{Pt}_{1-x} \mathrm{Mo}_{x}$ alloy with $x=0.2 \pm 0.1$. And, the activation barrier associated with this process is $3.8 \pm 0.5 \mathrm{eV}$. Based upon our results and the discussion in the following paragraphs, we suggest that the rate-limiting step controlling the observed $\mathrm{Pt}_{1-x} \mathrm{Mo}_{x}$ alloy transport along the $\mathrm{ZrB}_{2}$ thin film is the flux of Mo atoms.

All our experiments are carried out on electrontransparent XTEM samples of $\mathrm{ZrB}_{2} / \mathrm{Al}_{2} \mathrm{O}_{3}(0001)$. Polycrystalline $\mathrm{ZrB}_{2}$ layers, $\sim 85$-nm-thick, are grown on $\mathrm{Al}_{2} \mathrm{O}_{3}(0001)$ at $773 \mathrm{~K}$ by magnetically unbalanced magnetron sputter deposition from a stoichiometric $\mathrm{ZrB}_{2}$ target $(99.5 \%$ purity and $150 \mathrm{~mm}$ in diameter) using $\operatorname{Ar}$ (99.999\% purity) discharge in a modified Leybold-Univex 300 system (base pressure $\sim 7.5 \times 10^{-7}$ Torr) equipped with a circular unbalanced planar-magnetron $(152.4 \mathrm{~mm}$ in diameter, Gencoa PP 150). The substrates are centered parallel to the target and separated by $9 \mathrm{~cm}$, the Ar pressure is $3 \mathrm{mTorr}$, and the target power density is $3.5 \mathrm{~W} \mathrm{~cm}^{-2}$ yielding a $\mathrm{ZrB}_{2}$ deposition rate of $0.56 \mathrm{~nm} \mathrm{~s}^{-1}$. The incident metal $J_{\mathrm{Zr}}$ and ion $J_{\mathrm{Ar}+}$ fluxes and the ion energy $E_{\mathrm{Ar}+}$ bombarding the growing film are maintained constant such that $J_{\mathrm{Ar}+} / J_{\mathrm{Zr}}=0.6$ and $E_{\mathrm{Ar}+}=30 \mathrm{eV}$. The deposition system and the general film growth conditions are described in more detail in Refs. 22 and 23.

XTEM specimens are prepared via FIB milling using $\mathrm{Ga}^{+}$ions in a FEI Nova 600 Nanolab DualBeam FIB system equipped with a scanning electron microscope (SEM) and facilities for electron- and ion- beam induced deposition of 
$\mathrm{Pt}, \mathrm{W}$, and C. Prior to milling, the sample surface is first covered with a thin $(\approx 120 \mathrm{~nm})$ film of amorphous carbon deposited using $5 \mathrm{kV}$ and $6.3 \mathrm{nA}$ electron beams to minimize $\mathrm{Ga}^{+}$ irradiation induced damage to the sample surface. Additional carbon layers up to a nominal thickness of $1.5 \mu \mathrm{m}$ are deposited using $30 \mathrm{kV}$ and $0.3 \mathrm{nA} \mathrm{Ga}^{+}$ion beams. After $\mathrm{Ga}^{+}$ion milling, the sample is removed from the substrate and attached in situ in the FIB to a molybdenum lift-out TEM grid by ion-beam-assisted deposition of platinum from trimethyl platinum $\left(\mathrm{C}_{9} \mathrm{H}_{16} \mathrm{Pt}\right)$, a metalorganic precursor. Using EDS inside a FEI Nova 230 SEM, the composition of bare TEM grid is found to be 100 at. $\%$ Mo and that of FIBdeposited $\mathrm{Pt}$ to be $\sim 58$ at. $\% \mathrm{Pt}$ and $\sim 42$ at. $\%$ Ga. Final thinning of the $\mathrm{ZrB}_{2} / \mathrm{Al}_{2} \mathrm{O}_{3}(0001)$ sample to electron transparency is carried out using $10 \mathrm{kV} \mathrm{Ga}^{+}$beams. Fig. 1(a) is a typical SEM image of the as-prepared sample showing the overall sample geometry.

The XTEM sample is mounted in a Gatan 652 doubletilt heating holder and air-transferred into a $200 \mathrm{kV}, \mathrm{LaB}_{6}$, Philips CM20ST TEM (base pressure $\sim 10^{-7}$ Torr) for initial characterization. The sample is heated over a period of $3 \mathrm{~h}$ to $T_{a}=773 \mathrm{~K}$ in intervals of $100 \mathrm{~K}$ and held at each $T_{a}$ for approximately $20 \mathrm{~min}$. This procedure helps remove volatile adsorbates and $\mathrm{Ga}$ incorporated during FIB milling from the sample surface. Previous studies have shown that FIBinduced Ga segregates onto the surface in the form of spherical droplets. ${ }^{24-29}$ Within an hour of annealing at $T_{a} \sim 773 \mathrm{~K}$, most of the smaller Ga droplets disappear from the transparent regions of the sample via Ostwald ripening and are absorbed by larger droplets located at the thicker ends of the sample. $^{30}$

In situ annealing at higher temperatures $T_{a}$ between 1073 and $1173 \mathrm{~K}$ are carried out in the double $\mathrm{C}_{\mathrm{s}}$-corrected Linköping FEI 80-300 $\operatorname{Titan}^{3}$ scanning TEM (STEM) equipped with EDS and EELS spectrometers. In a typical experiment, the desired temperature is set and after reaching the set $T_{a}$, the sample is allowed to thermally equilibrate with its local environment before collecting the data. This occurs within $15 \mathrm{~min}$ at which point the thermal drift in the images is minimal $\left(\sim 1 \mathrm{~nm} / \mathrm{s}\right.$ at $T_{a}$ between $1073 \mathrm{~K}$ and $1173 \mathrm{~K})$. The temperatures are measured by a thermocouple built into the holder and is expected to be accurate to within $\pm 50 \mathrm{~K}$.

TEM images are acquired in bright-field mode at regular intervals of $1 \mathrm{~s}$ and $5 \mathrm{~s}$ during annealing at $T_{a} \geq$ and $<1123 \mathrm{~K}$, respectively. Typical image widths and pixel resolutions varied between 100 and $500 \mathrm{~nm}$ and 0.5 and $1.0 \mathrm{~nm} /$ pixel, respectively. TEM image magnifications $(13 \mathrm{k} \times-44 \mathrm{k} \times)$ and image acquisition times $(0.1-0.5 \mathrm{~s})$ were varied to check for the electron beam induced damage in the sample. We do not observe any such effects. SAED and EELS measurements are collected during annealing at high temperatures and also after cooling the sample to room temperature. EDS data are obtained at room temperature from selected points and along the lines of interest on the sample. TEM images are processed using the Gatan Digital Micrograph software. EDS and EELS are analyzed using the FEI Tecnai Imaging and Analysis software.

Figure 1(b) is a low-magnification STEM image of the $\mathrm{ZrB}_{2}$ thin film supported by $\mathrm{Al}_{2} \mathrm{O}_{3}(0001)$ at the bottom and covered with amorphous carbon at the top. In this imaging mode, the $\mathrm{ZrB}_{2}$ and the top $\mathrm{C}$ layers appear brighter and darker than the $\mathrm{Al}_{2} \mathrm{O}_{3}$ substrate due to mass contrast mechanism. SAED patterns acquired from the $\mathrm{ZrB}_{2}$ layers indicate that the film is polycrystalline exhibiting the expected hexagonal structure. At the $\mathrm{ZrB}_{2}-\mathrm{Al}_{2} \mathrm{O}_{3}$ interface, we note the presence of an 8-nm-thick layer that is darker in contrast compared to $\mathrm{Al}_{2} \mathrm{O}_{3}$. From the recorded EELS data, we find that this interfacial layer is primarily composed of $\mathrm{B}$ and $\mathrm{O}$. Complementary SAED patterns acquired from the interface indicated that the layer is amorphous. Based upon these results, we suggest that the interfacial layer is amorphous boron oxide. While the reasons leading to the formation of boron oxide at the interface are not clear, it is likely that this layer is a consequence of sputter deposition of $\mathrm{ZrB}_{2}$; similar results have also been reported during the growth of $\mathrm{ZrB}_{2}$ on $\mathrm{Si}$ and $\mathrm{SiC}$ substrates. ${ }^{31}$

Figures 2(a)-2(c) are representative bright-field TEM images acquired from the $\mathrm{ZrB}_{2}$ thin film sample during annealing at $T_{a}=1123 \mathrm{~K}$ as a function of time $t_{a}$. We observe a darker contrast develop along the $\mathrm{ZrB}_{2}$ film near the end of the sample attached to the TEM grid. We find that the length $L$ of this contrast increases with increasing $t_{a}$. This behavior is typical of all our annealing experiments carried out at $T_{a}$ between 1073 and $1123 \mathrm{~K}^{32}$ The observed phenomenon is qualitatively similar to silicidation of nanowires in contact with a metal. ${ }^{33,34}$ As a means to identify the origin of this contrast, SAED patterns were collected during annealing and EDS data after cooling the sample to room temperature. Figs. 2(d) and 2(e) show a bright-field TEM image and corresponding SAED pattern, respectively, acquired from the sample during annealing at $T_{a}=1123 \mathrm{~K}$. Interestingly, we observe diffraction spots characteristic of an $f c c$ structure and are nearly lattice-matched with Pt. In addition, we also
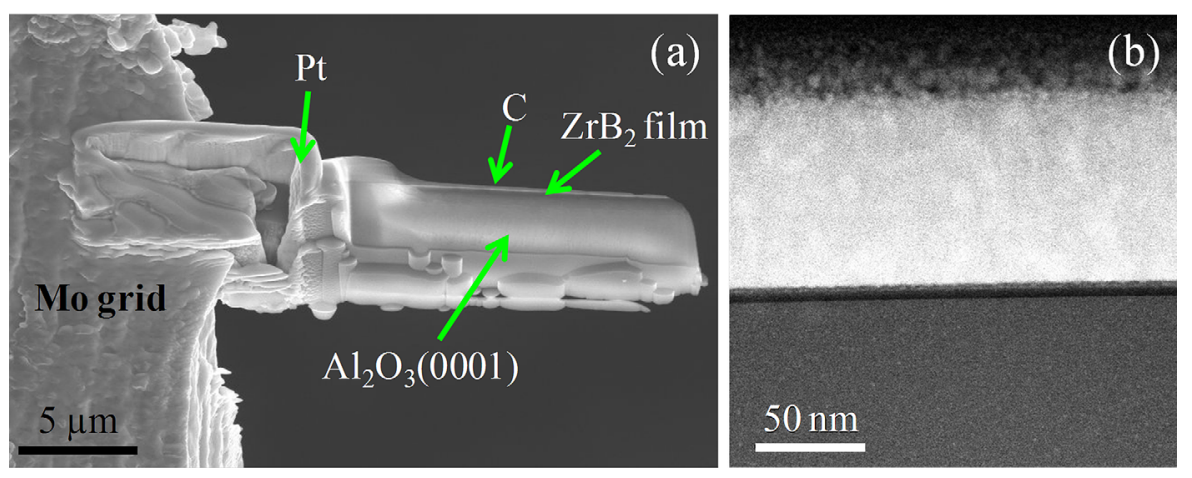

FIG. 1. Typical (a) SEM and (b) STEM images of a XTEM sample prepared via FIB milling and attached to a molybdenum grid by FIB deposited platinum. The STEM image in (b) shows amorphous $\mathrm{C}$ layer with implanted $\mathrm{Ga}, \mathrm{ZrB}_{2}$ layer, a thin boron oxide layer, and $\mathrm{Al}_{2} \mathrm{O}_{3}$ substrate from top to bottom, respectively. 

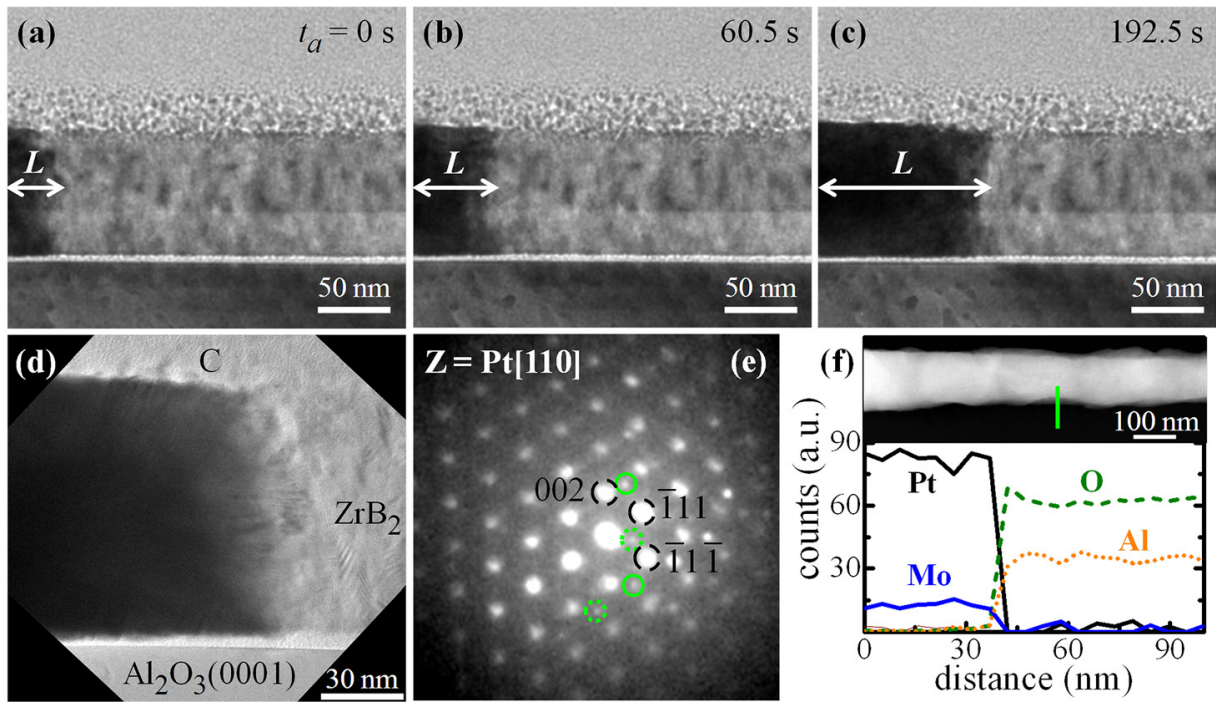

FIG. 2. (a)-(c) Representative bright-field TEM images acquired from $\mathrm{ZrB}_{2} / \mathrm{Al}_{2} \mathrm{O}_{3}(0001)$ sample as a function of time $t_{a}$ during annealing at temperature $T_{a}=1123 \mathrm{~K}$. The $\mathrm{ZrB}_{2}$ film surface is covered with amorphous carbon deposited prior to FIB milling and helps prevent FIB damage of the sample. The images also reveal the presence of an amorphous boron oxide layer at the $\mathrm{ZrB}_{2}-\mathrm{Al}_{2} \mathrm{O}_{3}$ interface, likely formed during sputter deposition of the $\mathrm{ZrB}$ thin film. The darker contrast visible in the images is due to the diffusing Pt-Mo alloy whose length $L$ along the $\mathrm{ZrB}_{2}$ film increases with time. (d) Higher magnification TEM image of the same sample at $1123 \mathrm{~K}$. (e) Selected area electron diffraction pattern of the region shown in Fig. 2(d) along the Pt[110] zone axis. The black dashed circles highlight the diffraction spots due to face-centered cubic lattice. The green dotted and solid circles indicate $\mathrm{ZrB}_{2}\{00.1\}$ and $\{11.1\}$ planes, respectively. (f) Energy dispersive spectral line intensities of $\mathrm{Pt}, \mathrm{Mo}, \mathrm{Al}$, and $\mathrm{O}$ acquired along the solid green line across the $\mathrm{ZrB}_{2}-\mathrm{Al}_{2} \mathrm{O}_{3}$ interface shown in the associated STEM image of the sample.

find fainter diffraction spots corresponding to hexagonal $\mathrm{ZrB}_{2}$, suggesting that the newly formed cubic phase coexists with the $\mathrm{ZrB}_{2}$ film, likely as a surface coating. EDS data acquired post annealing at room temperature from the darker contrast regions revealed the presence of significant amounts of Pt along with small amounts of Mo in addition to Zr. Fig. 2(f) is a typical plot of EDS intensities of $\mathrm{Pt}, \mathrm{Mo}, \mathrm{Al}$, and $\mathrm{O}$ along the line shown in the associated STEM image. For clarity, $\mathrm{Zr}$ spectral profile is not included in the plot. From the intensities of $\mathrm{Pt}$ and Mo lines measured both from EDS line scans and from selected points within the darker contrast regions, we estimate the composition as $80 \pm 10$ at. \% Pt and $20 \pm 10$ at. \% Mo. These results suggest that the observed contrast is due to a $f c c \mathrm{Pt}_{1-x} \mathrm{Mo}_{x}$ alloy with $x=0.2 \pm 0.1 .^{35}$

The observation of a crystalline $\mathrm{Pt}_{1-x} \mathrm{Mo}_{x}$ alloy phase superposed on $\mathrm{ZrB}_{2}$ film is surprising since neither Pt nor Mo were present in or on the as-deposited $\mathrm{ZrB}_{2}$ thin films prior to annealing. In our experiments, the only possible sources of Mo and Pt are, respectively, the TEM grid, which is primarily made up of Mo, and the FIB-deposited Pt intended to weld the sample to the grid. Moreover, the absence of diffraction spots from pure Mo and any intermetallics in the SAED patterns indicate that Pt and Mo prefer to exist as an alloy and that they do not react with $\mathrm{ZrB}_{2}$ at these temperatures. The EDS line intensities of $\mathrm{Pt}$ and Mo (see, for example, Fig. 2(e)) are fairly homogenous across the film, indicative of uniform distribution of $\mathrm{Pt}$ and $\mathrm{Mo}$ as expected for an alloy. We also note that the $\mathrm{Pt}_{1-x} \mathrm{Mo}_{x}$ alloy is observed only in the region around the $\mathrm{ZrB}_{2}$ film, and not on the top carbon layer or on the $\mathrm{Al}_{2} \mathrm{O}_{3}$ substrate (see Figs. 2(a)-2(c)). Based upon these results, we suggest that the FIB-deposited Pt alloys with Mo from the TEM grid and diffuses along the $\mathrm{ZrB}_{2}$ film. This is reasonable since the XTEM sample is in direct contact with both Pt and Mo and $\mathrm{Pt}(\mathrm{Mo})$ solid solutions are thermodynamically favorable at temperatures up to the melting point of $\mathrm{Pt}^{35}$ Also, our suggestion is consistent with the fact that the change in contrast is unidirectional away from the end of the sample attached to the Mo grid using Pt.

In order to better understand the kinetics of $\mathrm{Pt}_{1-x} \mathrm{Mo}_{x}$ alloy formation along the $\mathrm{ZrB}_{2}$ film, we measured $L$ as a function of $t_{a}$ and $T_{a}$. Fig. 3(a) shows plots of $L v$ s. $t_{a}$ data obtained at different temperatures between 1073 and $1173 \mathrm{~K}$. Note that there are two curves (solid and open brown circles) with different slopes at $T_{a}=1173 \mathrm{~K}$. In this experiment, the $L v s t_{a}$ data were collected during annealing first at $T_{a}=1173 \mathrm{~K}$ (solid brown circles) followed by $1073 \mathrm{~K}, 1098 \mathrm{~K}, 1123 \mathrm{~K}$, $1148 \mathrm{~K}$, and again at $1173 \mathrm{~K}$ (open brown circles). And, we find that the rate of increase in $L$ with $t_{a}$ at $1173 \mathrm{~K}$ is higher the first time than during annealing at the same temperature at a later time. Since our results suggest that electron beam irradiation has little effect on the observed phenomenon, the difference in $d L / d t_{a}$ at the same $T_{a}$ could be due to uncertainties in measuring (or attaining) the set temperature and/or due to time-dependent variation in the rate of mass transport along
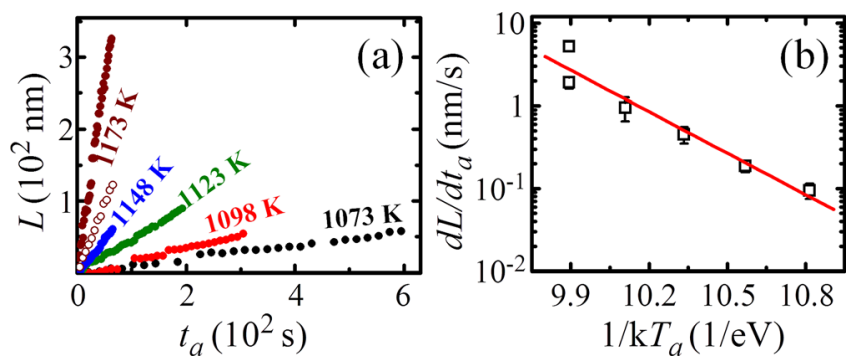

FIG. 3. (a) Plots of Pt-Mo alloy diffusion lengths $L v s$. annealing time $t_{a}$. Each color corresponds to data acquired at different annealing temperatures $T_{a}$ between 1073 and $1173 \mathrm{~K}$. (b) Arrhenius plot of $\mathrm{d} L / \mathrm{d} t_{a}$ vs. $1 / \mathrm{k} T_{a}$. The solid red line is a linear least squares fit to the data, the slope of which yields an activation barrier of $3.8 \pm 0.5 \mathrm{eV}$. 
the $\mathrm{ZrB}_{2}$ film. It is not clear which of these factors contribute to the observed difference. Nevertheless, at any given $T_{a}, L$ increases linearly with $t_{a}$, i.e., $d L / d t_{a}$ is constant. And, $d L / d t_{a}$ increases with increasing $T_{a}$. From the Arrhenius plot of $d L / d t_{a}$ vs. $1 / \mathrm{k} T_{a}$ shown in Fig. 3(b), using linear leastsquares fit to the data, we extract an activation energy of $3.8 \pm 0.5 \mathrm{eV}$.

We interpret these results as follows. The observed transport of $\mathrm{Pt}_{1-x} \mathrm{Mo}_{x}$ alloy involves three basic steps: (a) transfer of $\mathrm{Pt}$ and Mo atoms from their respective sources to the TEM sample, (b) diffusion of the metal atoms, and (c) formation of the $\mathrm{Pt}_{1-x} \mathrm{Mo}_{x}$ alloy. Since the formation enthalpy for Pt-rich $\mathrm{Pt}_{1-x} \mathrm{Mo}_{x}$ alloy is negative at these temperatures, ${ }^{36}$ we rule out this process as the rate-limiting step. Mass transport can occur via diffusion on $\mathrm{ZrB}_{2}$ surfaces, through the bulk of the $\mathrm{ZrB} 2$ film, and/or along the $\mathrm{ZrB}_{2} / \mathrm{C}$ and $\mathrm{ZrB}_{2} / \mathrm{Al}_{2} \mathrm{O}_{3}$ interfaces. Our TEM, SAED, EDS, and EELS data do not reveal the presence of Pt or Mo on the top carbon surface, bottom $\mathrm{Al}_{2} \mathrm{O}_{3}$, or the $\mathrm{ZrB}_{2} / \mathrm{C}$ and $\mathrm{ZrB}_{2} / \mathrm{Al}_{2} \mathrm{O}_{3}$ interfaces, based upon which we suggest that interfacial diffusion does not contribute to the transport of Pt and Mo atoms. Bulk diffusion of Pt and/or Mo atoms through the $\mathrm{ZrB}_{2}$ film, although possible, is less likely since SAED patterns acquired during annealing (see Fig. 2(e)) show diffraction spots characteristic of both the metal and the $\mathrm{ZrB}_{2}$ lattices. For both surface and bulk diffusion controlled kinetics, $L$ is expected to vary non-linearly with $t_{a}$, i.e., $d L / d t_{a}$ will not be constant. ${ }^{33,34}$ Moreover, the measured activation energy is considerably higher than the values expected for surface diffusion of Pt and Mo. ${ }^{37,38}$ Therefore, we suggest that the arrival flux of metal atoms onto the sample rather than diffusion along the $\mathrm{ZrB}_{2}$ film is the rate-limiting step. This is plausible since the contact area between the metals and the XTEM sample is considerably small and the interfacial bonding between the metals and the XTEM sample is likely to be poor. Interestingly, although $\mathrm{Pt}$ is in direct contact with the XTEM sample, we do not observe pure Pt on the sample; and while there is ample amount of Mo in the form of the TEM grid, we only observe Pt-rich $\mathrm{Pt}_{1-x} \mathrm{Mo}_{x}$ alloys and not Morich phases. We attribute these two observations to limited supply of Mo from the grid followed by faster diffusion of Mo compared to $\mathrm{Pt}$ on the $\mathrm{ZrB}_{2}$ surfaces.

In summary, we used in situ TEM and studied the thermal stability of metal-ceramic interfaces, specifically the kinetics of diffusion of $\mathrm{Pt}_{1-x} \mathrm{Mo}_{x}$ along $\mathrm{ZrB}_{2}$ thin films as a function of annealing time and temperature. Cross-sectional TEM samples were prepared via focused ion beam milling of polycrystalline $\mathrm{ZrB}_{2}$ thin films sputter-deposited onto $\mathrm{Al}_{2} \mathrm{O}_{3}(0001)$ substrates and attached to a molybdenum TEM grid by depositing Pt at one end of the sample. During annealing, we observed the motion of $f c c$-structured Pt-rich $\mathrm{Pt}_{1-x} \mathrm{Mo}_{x}$ alloy along the $\mathrm{ZrB}_{2}$ thin film. Based upon our results, we suggest that $\mathrm{Pt}$ and Mo form a Pt-rich solid solution and diffuse along the $\mathrm{ZrB}_{2}$ film surface. From the measured time- and temperature-dependent changes in interface contrast, we determine that the rate-limiting step is the supply of Mo atoms from the TEM grid. Our observations suggest that in situ microscopy studies of high-temperature phenomena require careful consideration of the preparation procedure, composition, and geometry of the sample and holder assembly. Based upon our results, we expect that the relative diffusivities of $\mathrm{Pt}$ and Mo are different and have important implications in the design of thermally stable interfaces for operation at high-temperatures.

We gratefully acknowledge support from the AFOSR (Dr. Ali Sayir) FA9550-10-1-0496, STINT, the Swedish Foundation for International Cooperation in Research and Higher Education, The Swedish Research Council, the Austrian Science Fund FWF, START Project No. Y371, and the Knut and Alice Wallenberg Foundation for the Ultra Electron Microscopy Laboratory in Linköping. We thank Mr. Noah Bodzin and the Nanoelectronics Research Facility in the UCLA Henry Samueli School of Engineering for assistance with focused ion beam milling.

${ }^{1}$ R. A. Miller, Surf. Coat. Technol. 30(1), 1-11 (1987).

${ }^{2}$ N. P. Padture, M. Gell, and E. H. Jordan, Science 296(5566), 280-284 (2002).

${ }^{3}$ D. R. Clarke and C. G. Levi, Annu. Rev. Mater. Res. 33, 383-417 (2003).

${ }^{4}$ D. R. Clarke, M. Oechsner, and N. P. Padture, MRS Bulletin 37, 891-898 (2012).

${ }^{5}$ K. Upadhya, J. M. Yang, and W. P. Hoffman, Am. Ceram. Soc. Bull. 76(12), 51-56 (1997).

${ }^{6}$ F. Monteverde, A. Bellosi, and L. Scatteia, Mater. Sci. Eng., A 485(1), 415-421 (2008).

${ }^{7}$ R. Raj, J. Am. Ceram. Soc. 76(9), 2147-2174 (1993).

${ }^{8}$ A. Passerone, F. Valenza, and M. L. Muolo, J. Mater. Sci. 47(24), 8275-8289 (2012).

${ }^{9}$ L. Silvestroni, D. Sciti, L. Esposito, and A. M. Glaeser, J. Eur. Ceram. Soc. 32(16), 4469-4479 (2012).

${ }^{10}$ Y. V. Naidich, V. S. Zhuravlev, I. I. Gab, B. D. Kostyuk, V. P. Krasovskyy, A. A. Adamovskyy, and N. Y. Taranets, J. Eur. Ceram. Soc. 28(4), 717-728 (2008).

${ }^{11}$ F. Valenza, M. L. Muolo, A. Passerone, G. Cacciamani, and C. Artini, J. Mater. Eng. Perform. 21(5), 660-666 (2012).

${ }^{12}$ W. G. Fahrenholtz, G. E. Hilmas, I. G. Talmy, and J. A. Zaykoski, J. Am. Ceram. Soc. 90(5), 1347-1364 (2007).

${ }^{13}$ M. L. Muolo, E. Ferrera, R. Novakovic, and A. Passerone, Scr. Mater. 48(2), 191-196 (2003).

${ }^{14}$ M. L. Muolo, E. Ferrera, and A. Passerone, J. Mater. Sci. 40(9-10), 2295-2300 (2005).

${ }^{15}$ A. Passerone, M. L. Muolo, and D. Passerone, J. Mater. Sci. 41(16), 5088-5098 (2006).

${ }^{16}$ A. Passerone, M. L. Muolo, F. Valenza, F. Monteverde, and N. Sobczak, Acta Mater. 57(2), 356-364 (2009).

${ }^{17}$ L. Silvestroni, H. J. Kleebe, S. Lauterbach, M. Muller, and D. Sciti, J. Mater. Res. 25(5), 828-834 (2010).

${ }^{18}$ D. Sciti, G. Bonnefont, G. Fantozzi, and L. Silvestroni, J. Eur. Ceram. Soc. 30(15), 3253-3258 (2010).

${ }^{19}$ A. Passerone, M. L. Muolo, R. Novakovic, and D. Passerone, J. Eur. Ceram. Soc. 27(10), 3277-3285 (2007).

${ }^{20}$ C. Mitterer, J. Komenda-Stallmaier, P. Losbichler, P. Schmölz, W. S. M. Werner, and H. Störi, Vacuum 46(11), 1281-1294 (1995).

${ }^{21}$ M. Samuelsson, J. Jensen, U. Helmersson, L. Hultman, and H. Högberg, Thin Solid Films 526(0), 163-167 (2012).

${ }^{22}$ P. H. Mayrhofer, M. Geier, C. Löcker, and L. Chen, Int. J. Mater. Res. 100(8), 1052-1058 (2009).

${ }^{23}$ I. Petrov, V. Orlinov, I. Ivanov, and J. Kourtev, Contrib. Plasma Phys. 28(2), 157-167 (1988).

${ }^{24}$ J. Fujita, T. Ichihashi, S. Nakazawa, S. Okada, M. Ishida, Y. Ochiai, T. Kaito, and S. Matsui, Appl. Phys. Lett. 88(8), 083109 (2006).

${ }^{25}$ W. J. MoberlyChan, D. P. Adams, M. J. Aziz, G. Hobler, and T. Schenkel, MRS Bull. 32(5), 424-432 (2007).

${ }^{26}$ R. Kometani, T. Ichihashi, S. Warisawa, and S. Ishihara, Jpn. J. Appl. Phys., Part 148 (6), 06fe01 (2009).

${ }^{27}$ Q. Hu and W. O’Neill, Appl. Surf. Sci. 256(20), 5952-5956 (2010).

${ }^{28}$ C. C. Lee, G. Proust, G. Alici, G. M. Spinks, and J. M. Cairney, J. Microsc. 248(2), 129-139 (2012).

${ }^{29}$ P. Philipp, L. Bischoff, and B. Schmidt, Nanotechnology 23(47), 475304 (2012). 
${ }^{30}$ S. Kodambaka, C. Ngo, J. Palisaitis, P. H. Mayrhofer, L. Hultman, and P. O. A. Persson, Appl. Phys. Lett. 102(16), 161601-161604 (2013).

${ }^{31}$ L. Tengdelius, M. Samuelsson, J. Jensen, J. Lu, L. Hultman, U. Forsberg, E. Janzén, and H. Högberg "DC magnetron sputtered ZrB2 thin films on $4 \mathrm{H}-\mathrm{SiC}(0001)$ and $\mathrm{Si}(100)$ " (submitted).

${ }^{32}$ See supplementary material at http://dx.doi.org/10.1063/1.4820581 for a set of TEM movies showing the contrast changes at four different temperatures.

${ }^{33}$ Y.-C. Chou, K.-C. Lu, and K. N. Tu, Mater. Sci. Eng. R 70(3-6), 112-125 (2010).
${ }^{34}$ A. Katsman, Y. Yaish, E. Rabkin, and M. Beregovsky, J. Electron. Mater. 39(4), 365-370 (2010).

${ }^{35}$ H. Okamoto, Desk Handbook: Phase Diagrams for Binary Alloys (ASM International, Materials Park, $\mathrm{OH}, 2000$ ).

${ }^{36}$ M. Y. Benarchid, N. David, J. M. Fiorani, M. Vilasi, and T. Benlaharche, J. Chem. Thermodyn. 41(3), 383-385 (2009).

${ }^{37}$ M. Ondrejcek, W. Swiech, G. Yang, and C. Flynn, Philos. Mag. Lett. 84(2), 69-77 (2004).

${ }^{38}$ M. Ondrejcek, W. Swiech, and C. P. Flynn, Surf. Sci. 600(20), 4673-4678 (2006). 